\title{
Research on Pre-control of Typhoon Disaster in Construction Site under Extreme Typhoon Climate-- Take typhoon Moranti as an example
}

\author{
Jianxun Deng ${ }^{1}, \quad$ Jing Chen ${ }^{2}$ \\ ${ }^{1,2}$ School of Architecture and Civil Engineering,Xiamen University,Xiamen 361005, China \\ Jianxun Deng, Dr. Assistant Professor. Department of Architecture and Civil Engineering, Xiamen University. Mainly Engaged in the \\ Research and Application of Urban disaster management, project risk management,BIM Technology, Real Estate Development and so \\ on.
}

\begin{abstract}
This article focuses on the damage to the construction project caused by the strong typhoon "Moranti" No. 14 of 2016 to the coastal city of Xiamen, and further analyzes the characteristics of the extreme typhoon climate, like strong destruction,extensive damage and obvious characteristics of the centralization, and the causes of the damage to the construction project. Leading to the conclusion that the risk items in the construction site mainly include personnel, scaffolds, and mechanical and electrical equipment, etc. Combined with the impact factors of duration, structure scale, economic exposure, and corporate management level, establishing the criteria for judging the extreme typhoon climate risk pre-control level and calculating the comprehensive level according to the level of each element and the weight distribution, and then, put forward pre-control measures and recommendations accordingly for government decision-making and construction companies' reference.
\end{abstract}

\section{Introduction}

At 14:00 on September 10, 2016, typhoon "Moranti"No. 14 was generated on the surface of the northwest Pacific Ocean. At 11 o'clock on September 12, it was strengthened into a super typhoon level and landed in Xiang'an coast, Xiamen at 3:05 am, which is the largest typhoon in southern Fujian since 1949, landed near the center with a maximum of level 15 winds $(48 \mathrm{~m} / \mathrm{s})$. And brought heavy storms to the coastal cities of southern China, with the maximum rainfall reaching $250 \mathrm{~mm}$. Three days later, 304.32 million people in 110 counties in Fujian and Zhejiang were affected. 28 people were killed in the disaster, 15 were missing, 84.19 million hectares of agricultural crops were affected, 801,300 people were transferred, and direct economic losses were 21.073 billion yuan ${ }^{[1]}$. This is the most serious natural disaster in Xiamen City in the past half century. It was also a "test" of the quality of Xiamen's construction projects. According to the "Code for Building Structural Loads GB50009-2015", the basic wind pressure in Xiamen in 50 years is $0.80 \mathrm{kN} / \mathrm{m}^{2}$, the basic wind pressure in 100 years is $0.95 \mathrm{kN} / \mathrm{m}^{2[2]}$. The 10 -minute average wind speeds for the 50-year and 100-year occurrences in Xiamen are $35.78 \mathrm{~m} / \mathrm{s}$ and $38.99 \mathrm{~m} / \mathrm{s}$, respectively. The typhoon wind speed is far greater than the design wind speed of the city once in a hundred years, even in accordance with the load specifications, the design of the structure is also unbearable.

In recent years, the typhoon storm disaster is a major security factor that seriously threatens the construction of coastal cities. The large-scale damage to buildings in the typhoon storm is the main cause of the huge wind disaster losses. Typhoon research has long attracted the attention of our government and academia. At present, there are a large number of studies on the causes of typhoon disasters ${ }^{[3,4]}$, risk assessment methods ${ }^{[5]}$, risk management ${ }^{[6]}$, and disaster prevention and mitigation ${ }^{[8]}$. However, there are few studies on the coupling effects of typhoon storms, how to reduce the risk of typhoon damage, monitoring and early warning on the field of building disasters. Based on this background, this paper proposes a study on the pre-control of typhoon disasters on the construction site for government decision-making and construction companies' reference.

\section{Damage to construction projects}

According to investigate and study the damage of

*Corresponding author: E-mail: djxun21cn@sina.com. 
"Moranti" typhoon in five districts and key construction sites in Xiamen, most of the construction sites in Xiamen were damaged by typhoon storms, and more than 10,000 work sheds collapsed, the construction site collapsed by about 402,200 meters, the external scaffolding damaged about 410,000 square meters, the safety net damaged about 2.08 million square meters, and there were more than 1,310 water piles in the foundation pit, 156 cranes damaged (including 82 tower crane collapsed or tilted, 70 hanging baskets, and 4 construction elevators). The direct economic loss was about 2 billion. In addition, many glass of doors and windows, building curtain walls, and billboards that are used in residential buildings, industrial plants, offices, and commercial buildings have been seriously damaged, severely damaging thousands of houses and damaging ten thousand houses. The typhoon brought severe impact on Taiwan, Zhejiang, and Guangdong.

Table 1. Damage to Construction Sites of Key Projects and Five Districts of Xiamen

\begin{tabular}{|c|c|c|c|c|c|c|}
\hline Items & Tong'an District & Ji'mei District & Xiang'an District & Hu'li District & $\begin{array}{l}\text { Hai'cang } \\
\text { District }\end{array}$ & Other Project \\
\hline Site enclosure(m) & 27000 & 36372 & 17632 & 11168 & 111534 & 115492 \\
\hline $\begin{array}{c}\text { External } \\
\text { scaffolding }\left(\mathrm{m}^{2}\right)\end{array}$ & 9000 & 43118 & 196838 & 2230 & 103978 & 67063 \\
\hline safe net $\left(\mathrm{m}^{2}\right)$ & 350000 & 200104 & 643864 & 139820 & 560961 & 528803 \\
\hline Accumulated Wate & 90 & 64 & 62 & 59 & 14 & 322 \\
\hline Work sheds (room) & 289 & 1406 & 2300 & 691 & 1822 & 1749 \\
\hline $\begin{array}{l}\text { Hoisting Machinery } \\
\text { (set) }\end{array}$ & 9 & 16 & 6 & 15 & 1 & 108 \\
\hline $\begin{array}{l}\text { Roof/Wall surface } \\
\left(\mathrm{m}^{2}\right)\end{array}$ & & 12800 & & & & \\
\hline
\end{tabular}

(Note: The data comes from post-disaster statistics on the construction of various departments in Xiamen)

From the statistical data, it is the Hu'li District, where the construction site is lightly affected, and the Xiang'an District, Hai'cang District, and the project managed by Xiamen City Quality Supervision Station are relatively serious losses. This may be related to the relatively mature development of Hu'li District and the rapid development momentum of Xiang'an, Hai'cang and other off-island areas.

\section{Characteristics and causes analysis}

\subsection{Characteristics of typhoon damage}

The devastating characteristics of the typhoon disaster on the construction site mainly include four characteristics: sudden, destructive, extensive damage, and concentrated characteristics.

Sudden The suddenness is mainly manifested in the dynamic changes of the typhoon's wind direction, and it is difficult to predict weather forecasts accurately. According to the data from the meteorological department, the accurate rate of natural disaster prediction at home and abroad can only reach more than $60 \%$, and the rest is not predictable. The unpredictable nature of the accident has caused great damage to the construction sites.

Destructive The destructive power of the typhoon is mainly caused by three factors: strong wind, heavy rain and storm surge. Typhoon often brings stormy weather when crossing the border, causing huge waves on the sea, which seriously threatens navigation safety. After landing, it can destroy crops, various construction facilities, etc., causing huge losses in people's lives and property.

Extensive The extensive destruction is mainly manifested in three aspects. First, the typhoon on the construction site has been destroyed in different areas and has been destroyed to varying degrees. Second, catastrophic damage to the typhoon on the construction site was not affected by the type of project, and they were damaged to varying degrees. From the survey data across the country, there were typhoon disasters in the housing construction project, municipal roads, bridges, railways, and airport projects, which has typical cases of destruction. Third, the typhoon-induced damage to the construction site, regardless of the scale and structure characteristics of the project, has been damaged to varying degrees. According to a survey of typhoon disasters on construction sites in Xiamen City in the past decade, steel construction projects, frame structures, multi-storey buildings, and high-rise buildings all suffered from varying degrees of damage. It can be seen that the destruction of typhoon disasters on the construction site has a wide range of damage.

Concentrated The characteristics of concentration mainly manifest in two aspects. First, the seasonal concentration, the general occurrence of typhoon disasters is mainly concentrated in the summer and autumn, the earliest occurred in early May, the latest occurred in November, these two seasons are frequent seasons of typhoon disaster. Second, regional concentration, typhoon disaster damage to the construction sites is mainly concentrated in the coastal 
areas, because the typhoon often formed in the western Pacific and the South China Sea waters, guided by the easterly airflow south of the subtropical high, moving to the west, Therefore, it often lands on the southeast coast of China to the coast of Vietnam.

\subsection{Analysis of causes of building damage}

Natural factors. Some of the buildings are located in geological hazards, such as some landslides, unstable slopes, etc. Under the influence of typhoons, the structure is unstable and collapses.

Improper using. Without the scientific and rational reform and design, the adding, building, demolishing or changing the use of the building without permission will change the carrying capacity of the building, which will lead to the main structure of the building to bury hidden safety hazards.

Low construction standard. There are still a lot of old buildings in Xiamen City. They were built in old age, old and outdated, and even built on the basis of empirical judgment, whose overall safety is low.

Construction quality. Poor construction results in safety hazards.

The building was damaged severely, such as tower cranes and trees, causing damage to houses.

The national standard's upper limit on the wind pressure of the design standard of the glass curtain wall is level 12, while the typhoon reaches 15 levels and the local area reaches 17 levels, far exceeding the upper limit of the design value.

The typhoon entrains rain to form a superposition force, which damages the glass curtain wall or the large-area balcony glass unbearably.

Due to the effect of wind shear between buildings, some buildings exacerbated the intensity of typhoons and formed a sudden increase in wind power.

Problems of using and management, some of the open fans were not fastened, the negative pressure caused by the typhoon dragged the sash outwards, and even some owners had privately changed the original designed and installed balcony glass and did not meet the safety standards.

\section{Setting of risk pre-control level}

Based on the typhoon disaster's destructive characteristics, causes of damage, and risk items in the construction sites, combined with the practical experience of pre-control of natural disasters at the construction sites, the basis for the pre-control elements includes duration, structure scale, economic exposure, and corporate management level. The longer the construction period is, the longer the risk coefficient is. Usually the more complex the engineering structure, the larger the scale, and the greater the risk coefficient. The greater the regional economic development level, the greater the regional risk coefficient, and the higher the management level of the company's construction projects the smaller the risk factor. In summary, the basis for the destruction of typhoon disasters on the construction site is the following four basic elements: duration, structure scale, economic exposure, and management level. Based on these four basic elements, a typhoon disaster destructive pre-control hierarchy system for construction sites was constructed.

Level setting for duration The typhoon hazard schedule for the construction sites is set to: the duration is defined as the 4th level within 90 days, the duration is 90-365 days as the 3rd level, the duration is 1-2 years as the 2 nd level, the duration is 2 years or more as the 1 st level ${ }^{[8]}$.

Level setting for structural scale The typhoon disaster structure scale of the construction sites is set to: basic projects such as general municipal projects and the construction of buildings under 5 floors are set to the 4th level, special projects and 5-10 floors are set to 3rd level, very special projects and 10 - 20 floors is set to 2 nd level; the special works and supertall building (20 floors or higher) are set to 1 st level.

Level setting for economic exposure In this paper, the economic development level of different regions is compared based on the ranking of GDP per capita. Therefore, the economic exposure level of typhoon disasters on the construction sites is set as: the pre-control level in the national ranking of per capita GDP in the top 5\% is defined as Level 1, 6-20\% is defined as Level 2, 21\%-50\% is defined as Level 3, ranking is defined as Level 4 after $50 \%$.

Level setting for corporate management Safety management is the sole criterion for measuring the management level of construction companies. Here, the author takes the safety accident rate (the ratio of the number of safety incidents to the total number of projects) in the past ten years as a index of the management level of construction companies. Therefore, the level of corporate management of typhoon disasters on the construction sites is set as: the rate of occurrence of safety accidents in the past 10 years is defined as level 4 within $1 \%$, the accident rate is defined as level 3 in $2 \%-5 \%, 6 \%-10 \%$ is defined as Level 2 , more than $10 \%$ is defined as Level 1.

Among these four influencing factors, due to the different contribution degree of each factor to the risk coefficient, it is necessary to assign weight coefficients. After consulting the expert opinions and literature review, the author believes that the management influence of the four influencing factors is the greatest, because it has the most direct impact, followed by the scale of the project structure, once again the impact of the duration, and finally the level of regional economic development. Guzhihui, domestic scholar also studies that compared to social vulnerability, natural vulnerability is the main factor affecting the relative damage rate of buildings ${ }^{[9]}$. Therefore, this paper considers the following weight distribution 
Table2.Weight Distribution of Afffected Factors for Risk

\begin{tabular}{|c|c|c|c|c|}
\hline Duration & Structural scale & Economic exposure & Corporate management & Total \\
\hline 0.2 & 0.3 & 0.1 & 0.4 & 1 \\
\hline
\end{tabular}

The overall level of typhoon disasters on the construction site should be considered in an integrated manner. The specific operations are as follows: First, the pre-control level of each element should be determined, second, the level of each element should be multiplied by the weight to obtain a comprehensive level, if there is a decimal, the rounding should be based on the rounding principle. Because the minimum level of each element is level 4, the highest level is level 1, and the range of comprehensive levels obtained is also should be between level 4 and level 1. Examples of operations are as follows:

Table3.Calculation for Comprehensive Level

\begin{tabular}{|c|c|c|c|}
\hline Duration $(0.2)$ & Structural scale $(0.3)$ & Economic exposure $(0.1)$ & Corporate management $(0.4)$ \\
\hline 1 & 1 & $-1-$ & 1 \\
\hline 2 & -2 & 2 & 2 \\
\hline 3 & $3<3$ & r w & 3 \\
\hline 4 & 4 & 4 & 4 \\
\hline
\end{tabular}

Calculation for comprehensive level in black: $2 * 0.2+3 * 0.3+1 * 0.1+4 * 0.4=3$ (level)

Calculation for comprehensive level in red: $4 * 0.2+2 * 0.3+3 * 0.1+4 * 0.4=3.3 \approx 3$ (level)

\section{Advice and measures for pre-control}

Pre-control measures are important guarantees to reduce the loss of typhoon disasters on the construction sites. According to the risk management theory, pre-control measures can be guaranteed in four aspects: organizational measures, management measures, economic measures, and technical measures.

Organizational measures Organizational measures are fundamental measures, which are mainly reflected in the establishment of agency and personnel, and the corresponding personnel are configured according to the previous section on the pre-control comprehensive level. Comprehensive level 1 pre-control should set up a leading group for typhoon disaster prevention and control, and set up professional pre-control teams, logistical support teams and emergency rescue teams, and more than 60 full-time pre-control personnel. Comprehensive level 2 pre-control should be set up for pre-control leadership groups and logistics support groups, rescue teams and other organizations, more than 40 part-time pre-control personnel. The integrated 3-level pre-control should set up a pre-control leading group and allocate more than 20 pre-control personnel. Comprehensive level 4 pre-control should be set up full-time pre-control project manager, and allocate more than 10 persons with pre-control and rescue personnel.

Economic measures To carry out pre-control of typhoon disasters on construction sites, funds are indispensable. It is recommended that special typhoon pre-control funds be set up, and special personnel be assigned to manage special funds to ensure funds are available in time when needed.

Technical measures Technical measures are mainly reflected in the protection of facilities and equipment and the treatment of hidden dangers.

Facilities and equipment protection. Rescue facilities are configured according to different pre-control levels.
As for the warning facilities, typhoon disaster warning facilities should be deployed at all construction sites. The early warning facilities mainly include special meteorological information receiving stations, high-broadcasting, walkie-talkies, and alarm devices.

Treatment of hidden dangers. Conduct regular safety inspections and troubleshooting of on-site equipment and temporary facilities and put in the necessary resources for maintenance, historical damage points should be reinforced and rectified to eliminating potential safety hazards effectively.

Management measures Management measures mainly include two aspects: system and training.

System construction. Pre-control of typhoon disasters at the construction sites must not only be guaranteed by organization, funds, and equipment, but also need a relatively complete system to guarantee. For other pre-control measures, a corresponding personnel incentive system, fund use system, facility management system, emergency rescue system, meeting system, and supervision and inspection mechanism can be established.

Quality training. With equipment, personnel, and systems, the lack of appropriate expertise in typhoon resistance will not work. Therefore, it is necessary to conduct training on the quality of anti-typhoon for all personnel on the construction sites to improve everyone's awareness of prevention and professional skills against typhoons.

\section{Summary}

The open-air nature of the operation has led to the inevitable loss of typhoons on the construction site, and the core of reducing the typhoon disaster loss is to do a good job on pre-control work beforehand. The combination of active control and passive control and active control as the main line can better achieve the purpose of disaster reduction.

In addition, disaster reduction work can only be achieved if it is built on a scientific management basis, with a reasonable management system, perfect rules and regulations, stable operational order, and complete and 
accurate information transmission. Organizational measures are the precondition and guarantee for other types of measures, and generally do not require any additional costs. Proper use can receive good results.

\section{Acknowledgment}

Fund: 1. science and technology project of Xiamen construction bureau (XJK2017-1-10)

2. science and technology project of Xiamen construction bureau(XJK2013-1-3)

\section{References}

1. Moranti[EB/OL].Sogou Encyclopedia:https://baike. sogou.com $/$ v153815921.htm? fromTitle $=\% \mathrm{E} 7 \% \mathrm{~A}$ C\%AC14\%E5\%8F\%B7\%E5\%8F\%B0\%E9\%A3\%8 E\%E8\%8E\%AB\%E5\%85\%B0\%E8\%92\%82, (Mar ch 17,2017)

2. $<$ Load Code for the Design of Building Structu res $>$ (GB 50009-2015)

3. Jianzhong Zhang, Yongheng Zhang, Guocai Zha ng,etc. The Natural Attributes and Social Attrib utes of Typhoon Disasters in Zhejiang Province from 1990 to 2012[J]. Mmteorology and Disast er Reduction Research.36(4):49-54(2013)

4. Liu, S., et al., Flood Control and Disaster Mitig ation in Shanghai. International Conference on Vulnerability \&amp; Ris..., (2014).

5. YIN Jie, WU Shaohong and DAI Erfu. Assess ment of Economic Damage Risks from Typhoon Disasters in Guangdong, China[J]. Journal of R esources and Ecology, 2012(02): 144-150.

6. YIN Jie, DAI Erfu and WU Shaohong. Compre hensive risk assessment and zoning of typhoon disasters in China[J]. Scientia Geographica Sinic a.33(11):1370-1376(2013).

7. Yong Chen, Xiaowei Chen. Study on Disaster P revention and Reduction of High-rise Buildings during Construction[J]. Science \& Technology V ision, 2014(01): 379-407.

8. Zhenhua Wu. Research on Pre-control of Natura 1 Disasters on Construction Site[J]. Architecture, 2012(1): 16-19

9. Zhihui Gu, Juan Wang, Yi Ge, Yu Chen. Study on Comprehensive Vulnerability Assessment M ethod for Typhoon Disaster in Regional Buildin $\mathrm{gs}[\mathrm{J}]$. Chinese Journal of Safety Science.26(2):1 08-113(2016). 